\title{
Performance of the INGV National Seismic Network from 1997 to 2007
}

\author{
Alessandro Amato and Francesco M. Mele \\ Istituto Nazionale di Geofisica e Vulcanologia, Centro Nazionale Terremoti, Roma, Italy
}

\begin{abstract}
Seismic monitoring in Italy has strongly improved since the 1997 Umbria-Marche earthquake sequence. This has made the National Seismic Network (Rete Sismica Nazionale RSN) a powerful tool both to rapidly locate and quantify thousands of earthquakes occurring in Italy every year, and to study the seismic activity in detail, accumulating an impressive high quality data set, that will be exploited in the coming years to understand earthquake processes and to investigate the deep structure.

In this paper we summarize and compare the basic features of the seismicity recorded in 2000 and 2006, before and after the implementation of the new RSN, showing that the number of well located earthquakes has more than doubled and that the completeness magnitude has dropped from $\sim 2.3$ to $\sim 1.7$. In addition, we concentrate on the evaluation of the current automatic location and magnitudes versus the revised ones, published routinely in the INGV bulletins. We show that the rapid estimates of locations and magnitudes are robust and reliable for most regions in Italy: more than $75 \%$ of the earthquakes are located in real time within $10 \mathrm{~km}$ from the «true» locations, whereas the rapid magnitudes ML are within \pm 0.4 from the revised values in $90 \%$ of cases. The comparison between real-time and revised locations shows that there are a few regions in Italy where a further network improvement is still desirable. These include all the off-shore regions, Calabria, western Sicily, the Alpine and Po Plain region, and some small areas along the peninsula.
\end{abstract}

Key words seismic networks - seismicity - real-time seismology - Italy

\section{Introduction}

The 1997 Umbria-Marche earthquake represents a milestone in the recent development of the seismic monitoring system in Italy. It was only in 2001, after the birth of the Istituto Nazionale di Geofisica e Vulcanologia (INGV) and the signature of the first 3-year agreement

Mailing address: Dr. Alessandro Amato, Istituto Nazionale di Geofisica e Vulcanologia, Centro Nazionale Terremoti, Via di Vigna Murata 605, 00143 Roma, Italy; e-mail: amato@ingv.it between INGV and the Department of Civil Protection (DPC), that the plan of an integrated monitoring system really took off. However, the 1997 earthquake marks the awareness of Italian seismologists that something had to be done to understand the earthquake process, and that a basic starting point was the availability of modern seismic and geodetic data. One main target was to fill the gap between permanent networks, developed during the ' 80 's with state-of-the-art instrumentation, which was basically still operational in the late ' 90 's, and the temporary networks that were already able to provide highresolution images of the active faults, though not in real time (e.g., Amato et al., 1998). An interesting point that came out after the long and complex analysis of data from the dense local network installed in 1997 in the Umbria-Marche region, is that we could predict the behaviour of 
fault activity (i.e., seismicity migration from one fault to another, activation of adjacent segments, etc.) during the sequence itself, if detailed data were available in real time (Deschamps et al., 2000; Chiaraluce et al., 2004). In this paper, we show how the National Seismic Network (RSN) improvement of the last decade allows us to better constrain the seismic activity, both for the rapid assessment of earthquake location and size, and for seismotectonic studies. We compare the seismicity before and after the network development, to show the improvements in the available seismic data. We also focus on the comparison of the automatic locations and magnitudes with the revised ones (bulletin data), to investigate to what extent the rapid estimates are well constrained. We concentrate on 2006, since starting from 16/4/2005 all the data from the upgraded RSN have been routinely used for bulletin data (http://iside.rm.ingv.it).

\section{The Italian National Monitoring System}

In 1997, the RSN managed by INGV consisted of about 90 real-time short period stations, with a sparse coverage and with low dynamic range. The main problems of such network were the low location accuracy in many regions, the time response, and the difficulties in determining reliable magnitudes, due to the low dynamic range of the telephone lines used for data transmission. For small earthquakes, at least 5 minutes were needed to get hypocenter locations and duration magnitudes (routinely used at that time), but even more time was necessary for M>4 earthquakes, for which the waveforms of the short-period network were mostly saturated. For moderate and large earthquakes, only data from broad band MedNet stations could be used for magnitude computation, but in 1997 they had dial-up connections and at least 15 to 30 minutes were needed to retrieve and analyze the data.

In 2000 (see table I) the monitoring system of the RSN counted continuous signal connections from 86 short period vertical seismometers and only ten three component 5 second or 1 second seismometers. The MedNet (equipped with STS-1 and STS-2 broad band sensors) contributed to the seismic network with fifteen dial-up or local recording stations in Italy and surrounding countries. In 2001 a marked improvement of the networks started (Amato et al., 2006), mainly regarding the RSN, but including MedNet (see http://mednet.rm.ingv.it ), the portable seismic network, and finally, after 2004, the National GPS network (see http://ring.gm.ingv.it/). Both the number of seismic stations and their quality increased significantly. Most of the new stations have a broad band seismometer, a strong motion sensor and a continuous GPS receiver, all connected in real time. Figure 1 shows the increase in the number of seismic stations connected in real time from 1988 to 2006 . As shown in the figure, the network had slowly grown between 1988 and 1997, and remained stable until 2000. The first slight increase (18 new stations) is evident in 2001, the first year of the DPC-INGV agreement. After that, a continuous increase in the number of stations connected in real time is well evident: in 2004-2005 the number of stations had doubled compared to 1997, and at the end of 2006 there were almost three times the number of stations than in 1997. More important, all the new stations have three-component mostly broad band seismometers, and this increased further the capacity of the network to detect and locate even small earthquakes, as

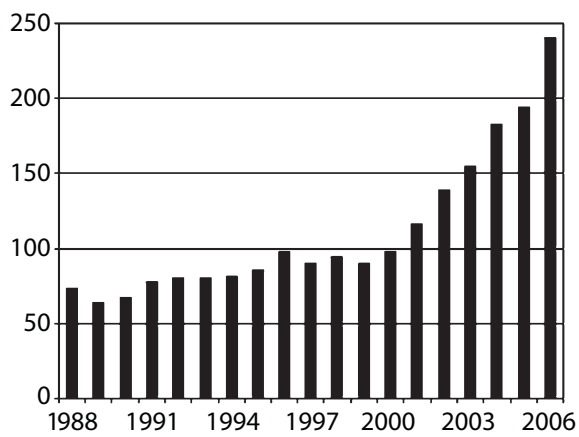

Fig. 1. Number of real-time stations connected to the INGV acquisition system from 1988 to the end of 2006. Most of the stations belong to the RSN but in the last few years stations of MedNet and of neighboring countries are also included. The strong impulse was given by the INGV-DPC first 3-year agreement, in 2001, and is still going on. 
well as studying the seismogenic properties of the sources and the deep structure of the Italian region. Tables I and II summarize the improvements, both in number of installations and quality of seismometers and connections used in 2000 and 2007.

The present configuration of the RSN (fig. 2 ) is good enough to guarantee rapid and accurate locations in most regions of Italy down to magnitude 2.5. Some work is still going on to improve the coverage in a few areas. The Umbria-Marche region is well covered today, with the exception of south-western Umbria. The integration of regional networks within the RSN in central-northern Italy proved to be very effective to investigate the low magnitude seismic activity in detail (De Luca et al., 2008).

The seismic data flow continuously, with maximum delays of a few seconds, into the IN-
GV acquisition system in Rome, where several procedures allow us to rapidly recognize local and distant earthquakes, locate them, compute magnitudes and produce reports and maps for the Civil Protection Department (DPC). For earthquakes in Italy, the first locations are generally ready after 20 seconds; within the first 40-50 seconds, an improved location with a preliminary estimate of magnitude (ML) is available (hereinafter called «rapid automatic solution»); all the data are processed and a final, more robust location and magnitude is available within 2-5 minutes after the origin time, depending on the magnitude of the event. The present agreement between INGV and DPC states that the first information with location and magnitude must be sent within the first 120 seconds after any potentially felt earthquake in Italy. More detailed information fol-

Table I. Numbers (last column) and characteristics of the RSN in year 2000, divided by sensor type (first column). The total number of sensors with real-time connection to the INGV centre in Rome was 96. Fifteen Very Broad Band stations belonging to MedNet were connected with dial-up lines used to download signals when needed; a few of them were only recorded locally.

\begin{tabular}{ccccc}
\hline \hline \multicolumn{5}{c}{ RSN station and connection characteristics -Year 2000 } \\
\hline Channel Type & Seismometer & Datalogger & Carrier & No. \\
\hline Short Period (1D) & S13 & Preston 13 bit & Analog & 86 \\
Short Period (3D) & S13 & Preston 13 bit & Analog & 4 \\
Enhanced Short (3D) & LE-3D 5s & Gaia 24 bit & Digital Serial Connection & 6 \\
VBB (3D) & STS-1 / STS-2 & Quanterra 24 bit & Dial-up / Local recording & 15 \\
\hline
\end{tabular}

Table II. Numbers (last column) and characteristics of the RSN at the end of 2007, divided by sensor type (first column). All the stations are continuously connected in real time with the INGV centre in Roma.

\begin{tabular}{|c|c|c|c|c|}
\hline \multicolumn{5}{|c|}{ RSN station and connection characteristics - Year 2007} \\
\hline Channel Type & Seismometer & Datalogger & Carrier & No. \\
\hline Short Period (1D) & S13 / SS1-Ranger & Preston 13 bit & Analog & 58 \\
\hline Enhanced Short (3D) & LE 5s & GAIA 24 bit & TCP-IP VPN & 24 \\
\hline Broad Band (3D) & $\begin{array}{l}\text { Trillium 40s } \\
\text { CMG 40T }\end{array}$ & $\begin{array}{l}\text { Nano. Trident } \\
\text { GAIA } 24 \text { bit }\end{array}$ & Satellite / VPN & 127 \\
\hline Very Broad Band (3D) & $\begin{array}{c}\text { STS2 } \\
\text { Trillium 120s }\end{array}$ & $\begin{array}{c}\text { Quanterra } \\
\text { Nanometrics }\end{array}$ & Satellite / VPN & 29 \\
\hline
\end{tabular}




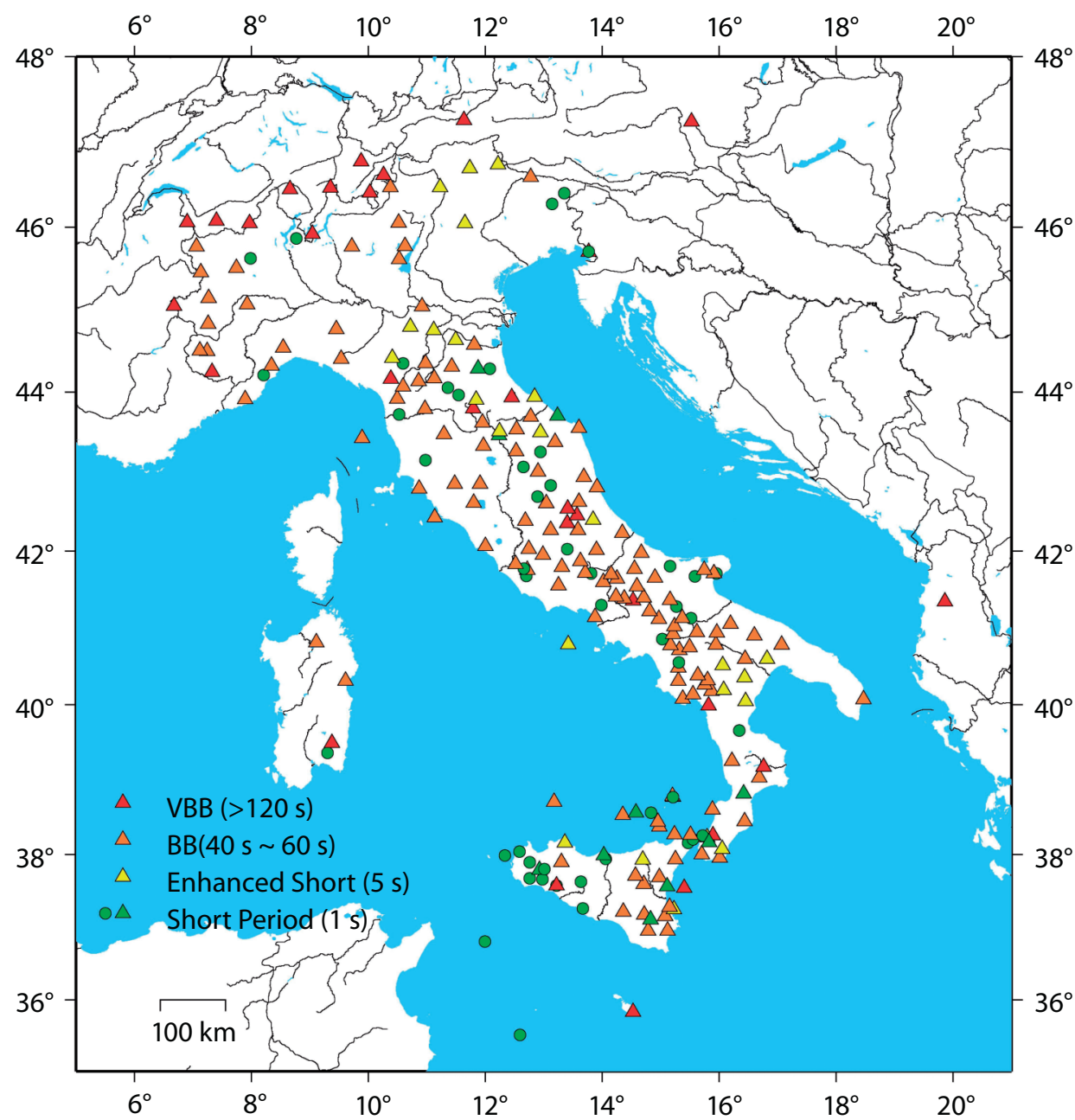

Fig. 2. Distribution of the stations connected to the INGV centre in Rome at the end of year 2007. Circles refer to 1 component vertical stations while triangles represent three component stations. The colours indicate the sensor type (see legend at the bottom left corner).

lows in the next few minutes. The accuracy of the preliminary locations is good in most regions of Italy. All the relevant events $(\mathrm{ML} \geq$ 2.5 , sometimes less depending on the earthquake felt pattern) are published on the web (http://cnt.rm.ingv.it/) soon after the rapid revision by expert personnel on duty at INGV.

Besides the real time connected stations, additional data reach the INGV monitoring system through e-mail containing automatic picks from a few networks: the DipTeRis - Genova University for NW Italy; the CRS of INOGS for NE Italy; the RSM regional network of the Regione Marche and INGV. These data are generally received within 5-15 minutes after an earthquake and contribute to refine the real time locations.

In the region of the 1997 earthquake sequence, the RSN has improved significantly, as will be shown later. De Luca et al. (2008) show how the integration of the RSN with the region- 
al networks gives important constraints for accurate earthquake location, yielding detailed images of the seismic structures in the crust and in the uppermost mantle of the region. Previously, both CSTI (2001) and Castello et al. (2006) showed the importance of integrating national with regional/local networks.

\section{Improvements in the seismic monitoring of Italy: the example of 2000 vs. 2006}

It is well known that a good earthquake catalogue is the first step to any seismotectonic study and hazard assessment analysis. In Italy, both historical catalogues (Gruppo di Lavoro CPTI, 2004) and instrumental data (Amato et al., 1997; CSTI, 2001; Chiarabba et al., 2005; Castello et al., 2006) have led to important discoveries on the way seismic energy is released throughout our region.

The epicentral maps in fig. 3 show the difference between the seismic activity recorded in 2000 and that of 2006. We chose these two years because neither of them had large earth- quake sequences that could significantly modify the yearly rate of earthquakes in the region. Moreover, most of the network development occurred after 2001, as seen in fig. 1, and reached a good configuration at the end of 2005 , although the improvements have continued in 2006 and 2007 and are still going on. A previous evaluation of the national seismic network between 1985 and 2002 was provided by Marchetti et al. (2006), who found a completeness magnitude of 2.4 for located earthquakes (Italian Seismic Bulletin) in the period 19851993, and 2.3 for located earthquakes in the period 1997-2002, but as low as 2.2 while analyzing poorly constrained detected (non-located) earthquakes. However, the period analyzed by Marchetti et al. (2006) was prior to the intense network improvement plan of the past few years (Amato et al., 2006).

The number of earthquakes plotted in the 2006 map (fig. 3) is approximately twice that of 2000, as expected thanks to the increased network. From the comparison between the two maps it is evident that: i) the number of small
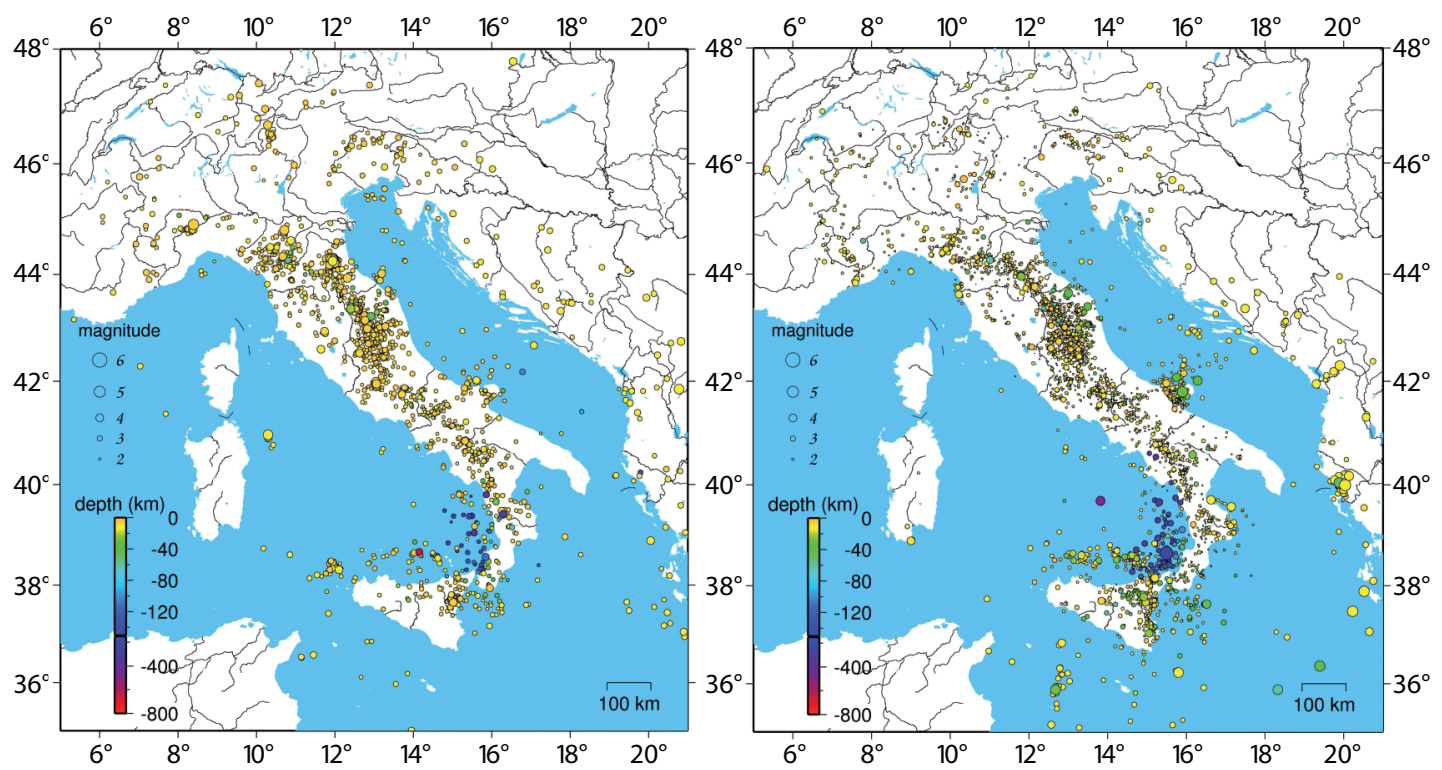

Fig. 3. Epicentral maps of Italian seismicity in 2000 (a) and 2006 (b). The number of epicenters plotted is more than 6,000 in 2006 and about 3,000 in 2000. Data are from the INGV bulletin. 
earthquakes has significantly increased, particularly in the central and northern Apennines; ii) the definition of seismic structures strongly improved in 2006, showing clearer trends; iii) the intermediate and deep seismic activity in the southern Tyrrhenian region is more evident; iv) there is more seismicity located off-shore (Sicily channel, Ionian sea, central Adriatic). The 2006 map shows that (with the improved network) one year contains most of the basic information on the seismic activity in Italy, depicting areas with frequent background seismicity and areas with few or no earthquakes. These latter could be due either to areas in which the magnitudes of the background seismicity is very low, below the detection threshold of the net, or to locked fault patches: see for instance the areas along the central-southern Apennines around lat. $42^{\circ} \mathrm{N}$ (Abruzzi), $41^{\circ} \mathrm{N}$ (SannioMatese), and lat. $39.5^{\circ} \mathrm{N}$ (Calabria). It is interesting to note that in 2006 we still see very clearly the fault zone of the 1980 Irpinia earthquake, marked by persistent aftershock activity. The 2006 map also shows that the earthquakes along the central axis of the Apennines are shallow (yellow circles, $\mathrm{z}<20 \mathrm{~km}$ ), whereas in the foredeep region to the east the average hypocentral depths are higher (green circles). Another area where the network is improved is the Gargano promontory, that in 2006 was very active with many earthquakes both in the upper and in the lower crust. Recent, detailed descriptions of the Italian seismicity were proposed by Castello et al. (2006), Chiarabba et al. (2005) and De Luca et al. (2008).

The network improvement can be evaluated also looking at the Gutenberg-Richter distribution for 2006 (fig. 4). The completeness interval for the whole region in 2006 was around 1.7, whereas in 2000 it was around 2.3-2.4 (Marchetti et al., 2006). The b-value for the whole 2006 data set (more than 6,000 earthquakes) was $0.84 \pm 0.02$, using the technique of Tinti and $\mathrm{Mu}-$ largia (1987). A very close value $(0.86 \pm 0.02)$ was obtained by Gasperini (2007) from the IN$\mathrm{GV}$ bulletin of the last two years. Gasperini (2007) also describes the variability in the bvalue for different periods of previous catalogues (CSI and INGV bulletin) suggesting that

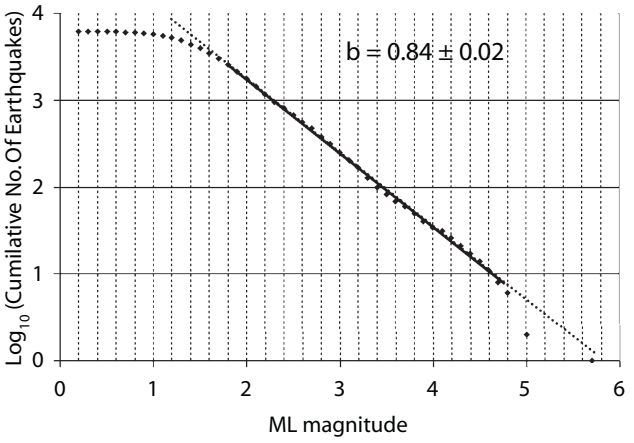

Fig. 4. Cumulated Gutenberg-Richter distribution from the 2006 Italian Seismic Bulletin.

it depends mostly on the choice of the completeness threshold (see also Peresan et al., 2000 and Castello et al., 2006).

\section{Automatic vs. Bulletin Locations}

In order to evaluate the quality of the real time location procedure, we compare the difference between automatic locations and revised bulletin solutions, considered here as the reference ones, for the year 2006. The automatic locations are computed from the $\mathrm{P}$ readings obtained automatically with an STA/LTA algorithm, applied in three different frequency bands (Taccetti et al. 1989). The same algorithm is applied to retrieve the $\mathrm{S}$ arrival times on the horizontal components. However, due to the $\mathrm{P}$ wave coda, the number of automatic $\mathrm{S}$ arrival times is much lower than that of $\mathrm{P}$ waves. The bulletin solutions are obtained after a careful analysis of all the waveforms associated with each event, performed by well trained personnel.

Figure 5 shows the distribution of weighted RMS (WRMS) for all the $\mathrm{M} \geq 2.5$ earthquakes that occurred in 2006. Three different locations are compared for the whole data set: the revised bulletin solutions, the rapid and the final automatic locations (see below for the explanation of the last two categories). The bulletin locations have WRMS centred at about $0.4 \mathrm{~s}$, where- 


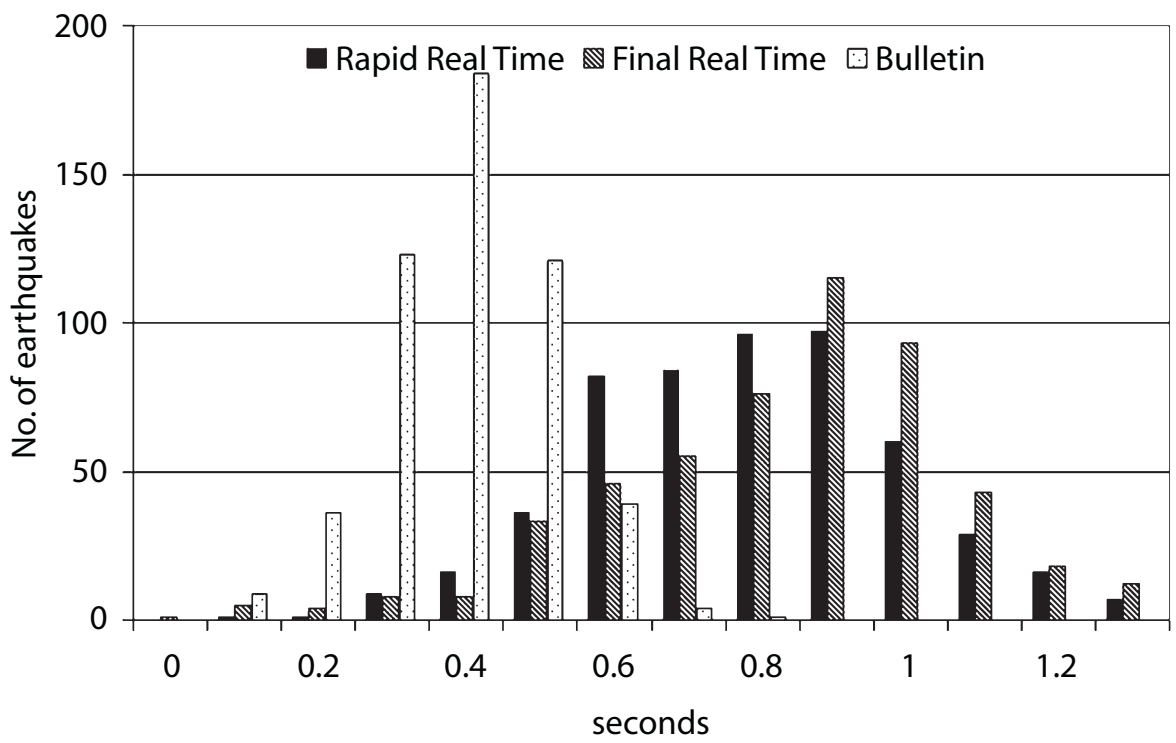

Fig. 5. Distributions of the weighted RMS of the residuals for Bulletin, final realtime, and rapid realtime locations in 2006.

as both automatic solutions have larger WRMS (mean around 0.8s). This is because both the rapid and the final automatic solutions are computed with all the automatic pickings, without any selection.

Moreover, the rapid automatic solutions have slightly lower WRMS compared to the final ones (fig. 5), since the former are determined with few close stations, while the latter use all the associated arrival times, including distant stations for which the poor knowledge of the velocity structure has larger effects.

Figure $6 a$ reports the location differences for all the 2006 earthquakes with magnitude $\mathrm{ML} \geq 2.8$ and with the first station within 80 $\mathrm{km}$. The figure shows well that for all the events located within the network the automatic locations are very close to the «true» locations (i.e., within 5-10 km). Larger discrepancies (around $10-20 \mathrm{~km}$ ) are seen for earthquakes located offshore (mostly north and south of Sicily). The longer arrows are related to deep events in the Southern Tyrrhenian sea, that were erroneously located at shallow depth by the automatic procedure.

A particularly unlucky circumstance is when two earthquakes occur at about the same time in two different locations. These «double» earthquakes (not included in fig. 6a) are not as infrequent as one might suppose. Figure $6 b$ shows such occurrences for 2006: eleven wrong real-time locations due to quasi-contemporaneous earthquake pairs occurring at distant hypocenters. The typical case is when two earthquakes in two regions sufficiently far away from one another occur within seconds of delay. The differences of their origin times (in the Bulletin) ranged from $2 \mathrm{~s}$ to $36 \mathrm{~s}$. The automatic procedure associates all the available picks and finds a common realistic hypocenter midway from the two real locations (see for instance the faked mixed event in the Adriatic offshore, which is due to two contemporaneous events, one in the Gargano promontory and one in central Italy, respectively). Similar cases occurred for the false events near the Tyrrhenian coast. Such mid-way solutions are produced when the two earthquakes have similar magnitude and similar number of associated stations.

Another case is when one event is stronger, or anyway has more associated stations, while the second contemporaneous one has only a 

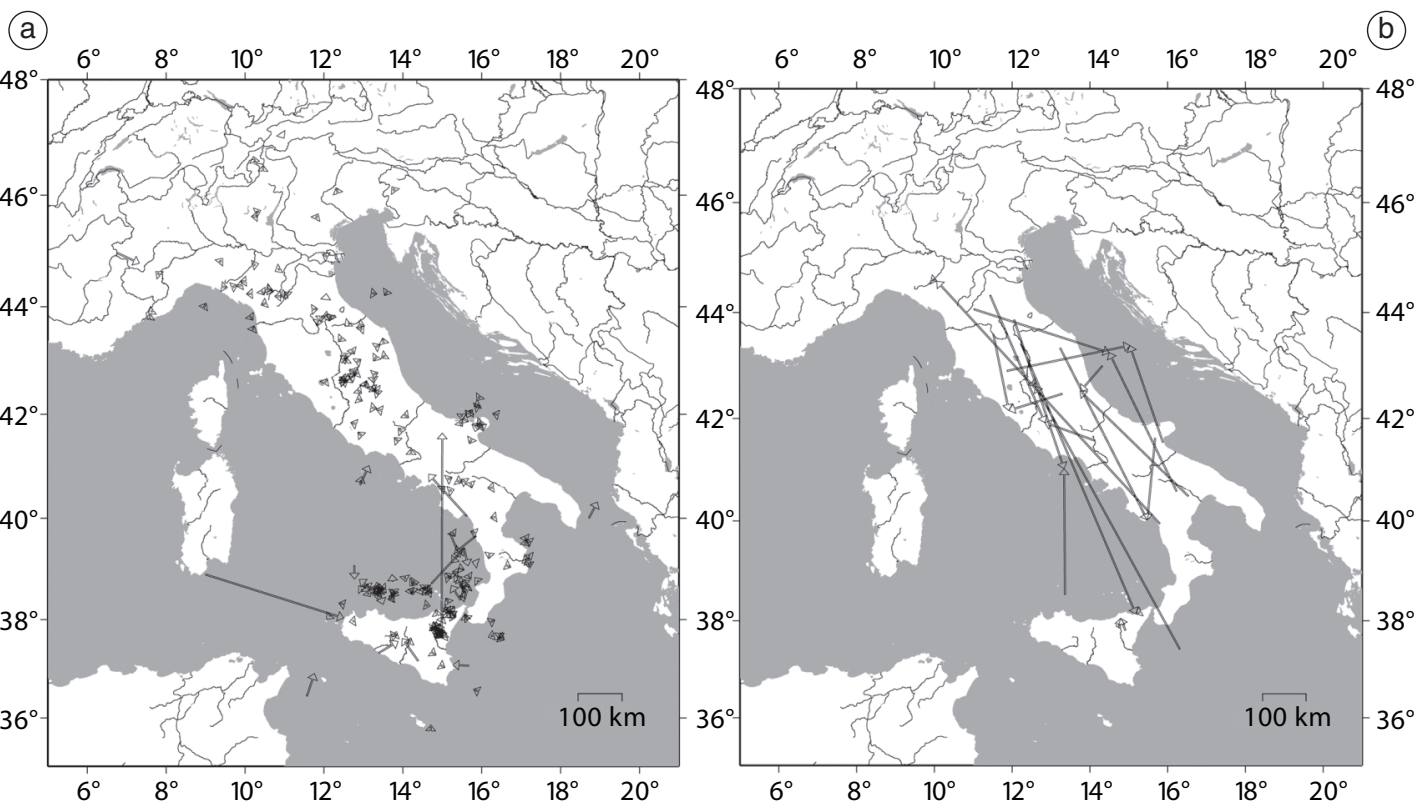

Fig. 6a,b. a) Left: mislocation vectors between final automatic and revised locations for earthquakes with ML $\geq$ 2.8 occurred in 2006 . The arrows point to the revised solution. b) simultaneous couples of events erroneously located in real time as single earthquakes during 2006. The arrows point to the mislocated epicenters, the lines end in the two correct locations.

few stations triggered. In this case the automatic solution is close to the larger one, as for the northernmost event in fig. 6b, in northern Apennines. The second event, erroneously associated with this one, is located very far away, near Calabria. It is important to note that the INGV real-time monitoring system involves $\mathrm{H} 24 / 7$ onduty personnel, who correct such anomalies of the automatic procedures through a rapid revision within the first few minutes after any event.

Ten other events were not recognised by the automatic procedures, and only manually located by the analysts, because other earthquakes preceded them by a few seconds or a few tens of seconds in the same or in a very close location (not shown in fig. 6b).

In order to quantify the number of good automatic solutions, we show in fig. 7a the percentage cumulated distribution of the discrepancies between (final) automatic and bulletin epicentral locations (for year 2006 events with $M L \geq 2.5$ ). The figure shows that more than
$75 \%$ of the differences in distance between the two locations is lower than $10 \mathrm{~km}$. The remaining $25 \%$ includes mostly off-shore events in the Adriatic, Tyrrhenian and Ionian seas (see also fig. 6).

In order to further investigate the performance of the real time process, we also compare the rapid automatic location with the revised one (fig. 7b). The automatic system running for the real time monitoring computes a first rough location when at least three picks are available. This is generally done within 20 seconds after the earthquake origin time. Then, a new solution is computed after every 10 seconds, using data from the stations that were triggered and associated in that time window. Our «rapid» solution refers to the third automatic location, computed about 40-50s after the earthquake origin time. For earthquakes with $\mathrm{ML}>3.5$, at least 6-7 subsequent solutions are determined, while for ML>4 about 10 solutions are obtained.

The results are shown in fig. $7 \mathrm{~b}$. The basic 

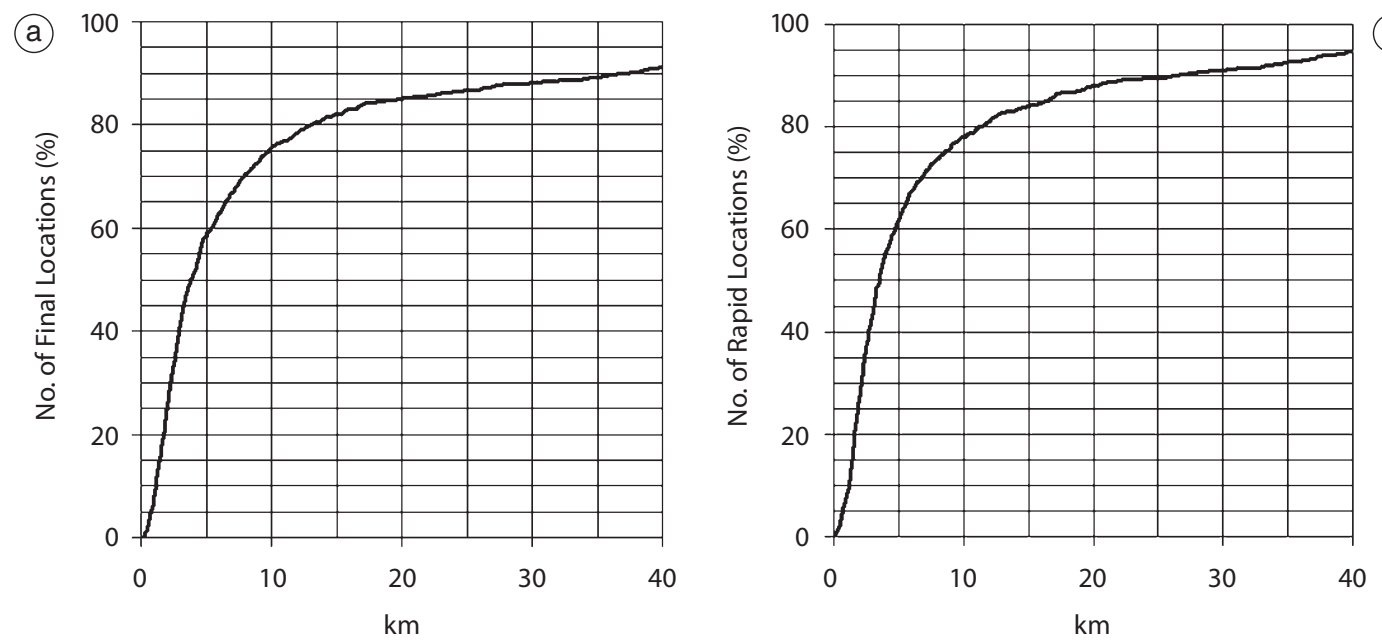

Fig. 7a,b. Cumulative distribution of the horizontal distances between the automatic locations and the Bulletin ones (year 2006, ML $\geq 2.5$ ): a) final automatic vs. bulletin solutions; b) rapid ( 40seconds) vs. bulletin solutions.

features observed for the rapid locations are very similar to those obtained for the final solutions, with a slight improvement in the number of good locations (i.e. about $80 \%$ of the events are within $10 \mathrm{~km}$ from the bulletin locations). This comparison demonstrates that the RSN is dense and rapid enough to well determine earthquake locations and magnitudes within the first 40 seconds from the origin time throughout the Italian territory. Indeed, for the well covered regions, like those in most of peninsular Italy and eastern Sicily, we have good automatic locations even at the first trial, i.e. 20 seconds after the earthquake. Olivieri et al. (2008) show that an Early Warning with the RSN data is possible in the regions where the network is dense.

\section{Automatic vs. Bulletin Magnitudes}

The present automatic procedures running on the RSN include the estimate of local magnitude (ML). For many years in the 80's and 90's, the first routine magnitude provided by the RSN was the coda (or duration) magnitude (MD), to which a later ML computation based on dial-up broad band MedNet stations fol- lowed, to avoid underestimated values for larger events. This was the case of the 1997 Umbria-Marche earthquakes. The MedNet ML was generally good, but it suffered from a sparse coverage and slow connections. Starting from 2003 the official magnitude released by INGV to DPC is the Richter or local magnitude ML, obtained from the numerous three-component stations of both RSN and MedNet available in real time. The final automatic ML is determined after all the waveforms within $600 \mathrm{~km}$ are recorded for a specific earthquake within or around Italy. This happens after about 1 minute for small earthquakes ( $\mathrm{ML}<2.5)$, but it takes 34 minutes for larger shocks, due to the large propagation area (and time) necessary for the wave front to reach distant stations. However, in order to have a more rapid estimate, in 2004 we started to calculate ML when a few close three-component stations provided non-saturated data, i.e. less than 1 minute after the earthquake origin time. We discard the closest stations (within $30 \mathrm{~km}$ from the epicenter) to avoid a possible overestimation of the magnitude. This «rapid» magnitude proved to be very useful to give the first information to the Civil Protection (due within 2 minutes after each poten- 

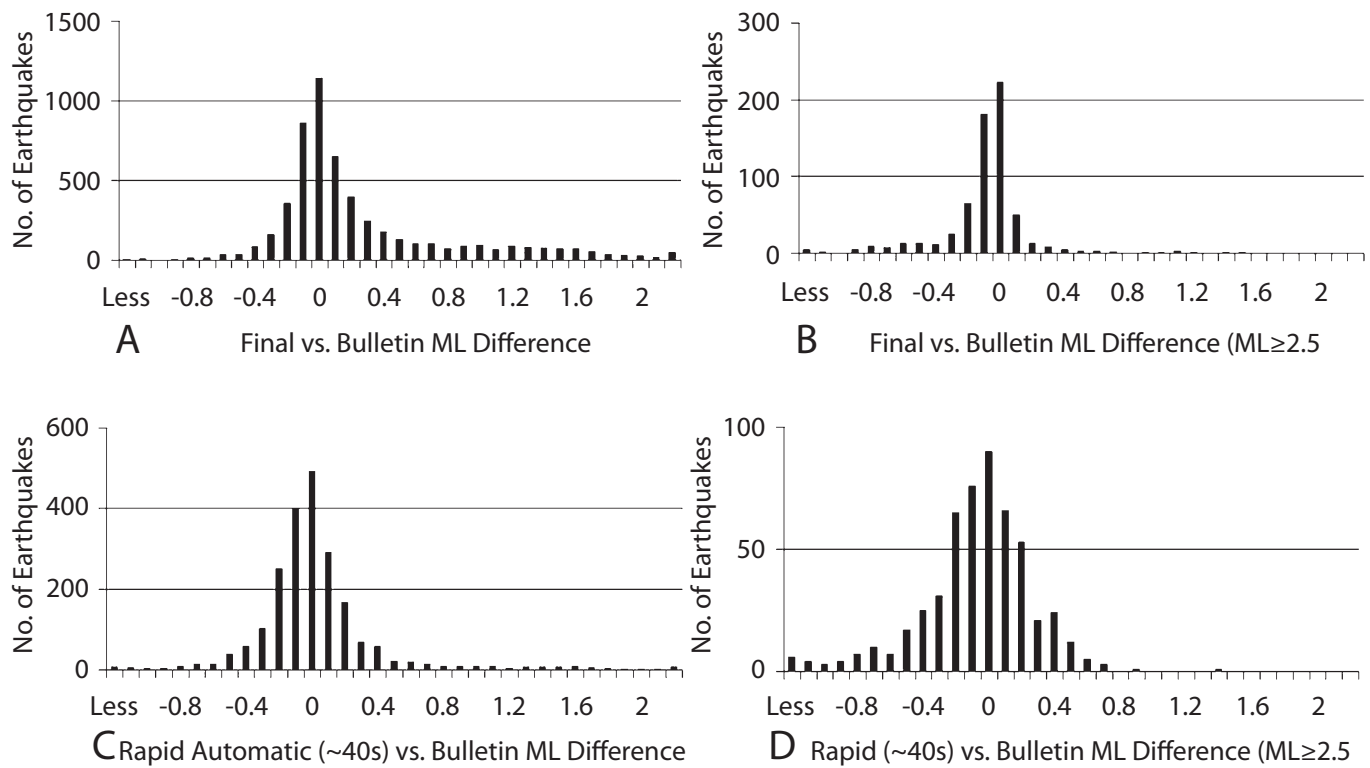

Fig. 8a-d. Comparison between automatic and bulletin magnitudes (ML) for year 2006. (a) Final automatic vs. bulletin, all earthquakes; (b) as in (a) for events with $\mathrm{ML} \geq 2.5$; (c) Rapid ( 40seconds) vs. bulletin, all earthquakes; (d) as in (c) for events with $M L \geq 2.5$. Note the different scales of the Y axes.

tially felt earthquake, i.e. $\mathrm{ML} \geq 2.5$ approximately).

As usual, we compute an ML station magnitude value using a synthetic full wave WoodAnderson seismogram obtained deconvolving the true signal of a horizontal component with the instrument response function (this operation gives the true velocity of the ground, if applied to a velocimeter signal) and then convolving the obtained signal with the theoretical response of the Wood-Anderson seismometer. A correction function with distance suitable for the whole of Italy has not been computed yet on a large homogeneous data set, although some works have been done on this issue (Bindi et al., 2005; Gasperini, 2002; Castello et al., 2007) and other investigations are in progress. At the moment we are using the relation found by Hutton and Boore (1987), valid for California:

$$
\begin{gathered}
\mathrm{ML}=\log _{10}(a m p)+1.110 \log _{10}(\text { hd } / 100)+ \\
+0.00189(h d-100)+3.0
\end{gathered}
$$

where amp is the peak-to-peak maximum amplitude (in mm divided by 2 ) of the Wood-Anderson synthetic record, and hd is the hypocenter-station distance in kilometres (where, as for Hutton and Boore: $10 \mathrm{~km}<\mathrm{hd}<600 \mathrm{~km}$ ). The above relation, computed for southern California, mostly fits the Italian data for stationhypocenter distances greater than 100 kilometres, whereas it overestimates the local magnitude at closer stations (M. Di Bona, personal communication). As a result, the magnitudes of moderate earthquakes (up to magnitude 6), recorded by many distant stations, are still reliable, while the magnitudes of small events could be biased by the prevalence of close stations and will require further investigations. In order to reduce this bias effect, we discard from the computation of local magnitude the stations within $30 \mathrm{~km}$ from the epicenter (because errors in the hypocentral determination can cause large relative errors in the station-hypocenter distances and thus in the station magnitudes).

In order to estimate the accuracy of the automatic ML, we compare the final automatic 
and the rapid one with the revised ML, obtained from bulletin data. Figure 8 (a through d) summarizes these comparisons, showing the whole data set (8a and 8c for final and rapid ML, respectively) and a subset of data, limited to earthquakes with $\mathrm{ML} \geq 2.5$ ( $8 \mathrm{~b}$ and $8 \mathrm{~d}$ ). Figure 8 a shows that the differences between automatic and bulletin ML are mostly around 0.0 , with $74 \%$ of values within \pm 0.4 . However, several positive values in the range 1.0-2.0 difference are observed. This is due to the smaller earthquakes, for which the automatic values tend to overestimate the revised ones, as described before. Figure $8 b$ shows indeed that, if we consider only earthquakes with $\mathrm{ML} \geq 2.5$, the distribution is well centred around 0.0 , with $89 \%$ differences within \pm 0.4 .

Looking at the «rapid» ML (the one computed at the third automatic location, i.e. after $\sim 40$ s), we see that (fig. 8c) the differences with the revised ML are very well distributed around 0.0 , with $89 \%$ of the values within \pm 0.4 . The same trend is observed if we consider only earthquakes with $\mathrm{ML} \geq 2.5$ (fig. 8d), demonstrating that the rapid ML is robust and reliable, at least for moderate events. It must be mentioned that an automatic procedure for determining automatic moment tensors and $\mathrm{Mw}$ is running as well at INGV, both to understand the type of earthquake faulting and to have a more robust estimate of the earthquake size, particularly for large events.

When determining both automatic and revised ML values, we compute the trimmed mean by averaging ML values obtained on all the horizontal channels with the Huber method that eliminates the outliers of the distribution (Huber, 1981). With the present RSN configuration, we have typically more than 50 estimates for $\mathrm{ML} \geq 3$ earthquakes, that warrant re-

Table III. Quality Ranking Q1 used to class hypocenters according to goodness-of-fit and formal errors. An earthquake has quality D if at least one of the conditions is not verified. The WNP value results from the sum of the relative weights (which can range between 0.0 and.1.0) assigned to the associated arrival times. The score shown in the last column is used in combination with Q2 score (see table IV) to define a unique quality scale used in fig. 9.

\begin{tabular}{cccccc}
\hline $\begin{array}{c}\text { Quality } \\
\text { Q1 }\end{array}$ & $\begin{array}{c}\text { Weighted } \\
\text { RMS }\end{array}$ & $\begin{array}{c}\text { Horizontal } \\
\text { Error }\end{array}$ & $\begin{array}{c}\text { Vertical } \\
\text { Error }\end{array}$ & $\begin{array}{c}\text { Weighted Num. } \\
\text { of phases (WNP) }\end{array}$ & $\begin{array}{c}\text { Q1 } \\
\text { Score }\end{array}$ \\
\hline $\mathrm{A}$ & $<0.45 \mathrm{~s}$ & $<2 \mathrm{~km}$ & $<4 \mathrm{~km}$ & $\geq 3$ & 1.5 \\
$\mathrm{~B}$ & $<0.90 \mathrm{~s}$ & $<5 \mathrm{~km}$ & $<10 \mathrm{~km}$ & $\geq 3$ & 0.5 \\
$\mathrm{C}$ & $<1.50 \mathrm{~s}$ & $<10 \mathrm{~km}$ & n.a. & $\geq 3$ & -0.5 \\
$\mathrm{D}$ & $\begin{array}{c}\text { Worse } \\
\text { than above }\end{array}$ & $\begin{array}{c}\text { Worse } \\
\text { than above }\end{array}$ & $\begin{array}{c}\text { Worse } \\
\text { than above }\end{array}$ & $\begin{array}{c}\text { Worse } \\
\text { than above }\end{array}$ & -1.5 \\
\hline
\end{tabular}

Table IV. Quality Ranking Q2 used to class hypocenters according to station geometry and distance of the closest station from the epicenter. An earthquake has quality D if at least one of the conditions is not verified.

\begin{tabular}{ccccc}
\hline \hline $\begin{array}{c}\text { Quality } \\
\text { Q2 }\end{array}$ & $\begin{array}{c}\text { Maximum } \\
\text { Azimuthal Gap }\end{array}$ & $\begin{array}{c}\text { Closest } \\
\text { Station Distance }\end{array}$ & $\begin{array}{c}\text { Weighted } \\
\text { Num. of phases }\end{array}$ & $\begin{array}{c}\text { Score } \\
\text { Q2 }\end{array}$ \\
\hline A & $<90$ & $<10 \mathrm{~km}$ or $<$ Depth & $\geq 6$ & 3 \\
B & $<135$ & $<20 \mathrm{~km}$ or $<2 *$ Depth & $\geq 6$ & 1 \\
$\mathrm{C}$ & $<180$ & $<100 \mathrm{~km}$ & $\geq 6$ & -1 \\
$\mathrm{D}$ & Worse than above & Worse than above & Worse than above & -3 \\
\hline
\end{tabular}


(a)
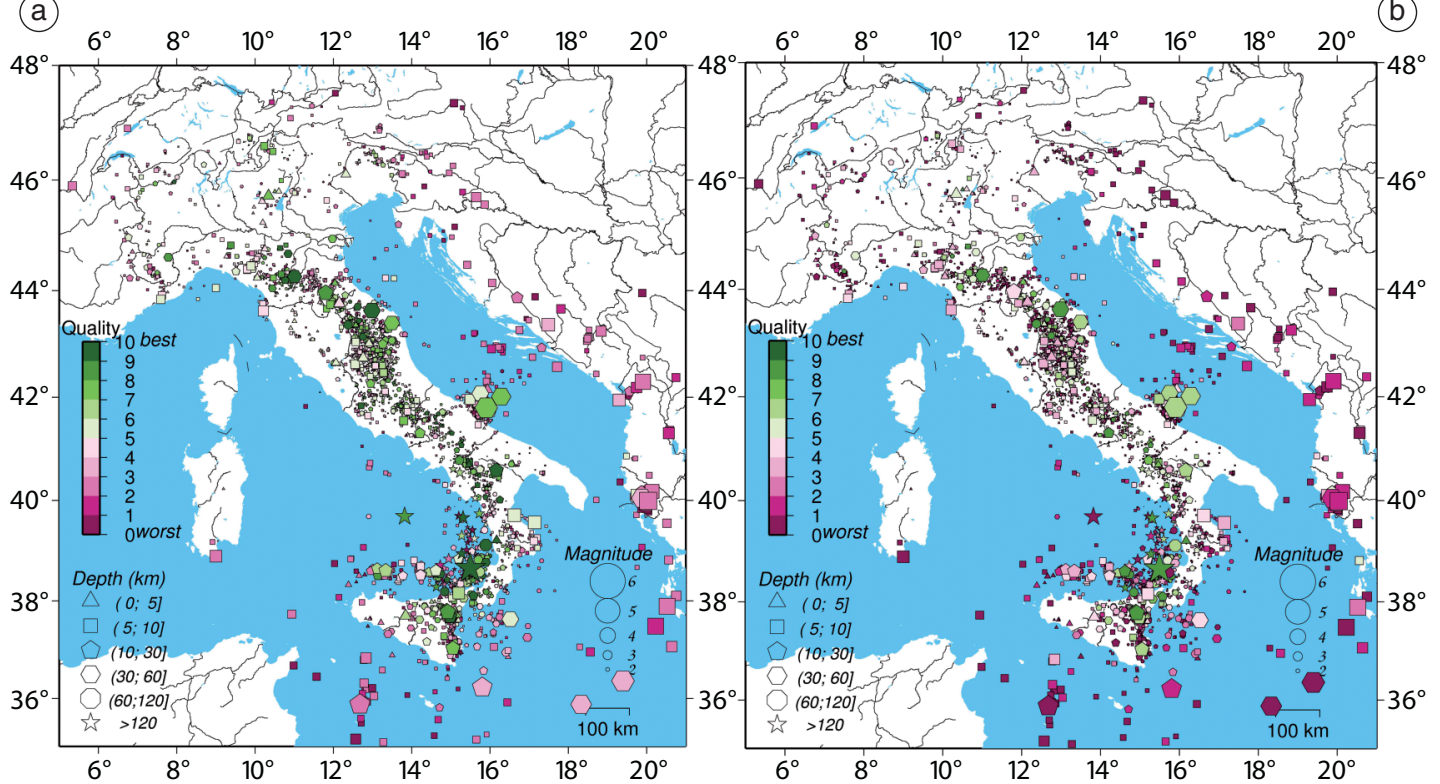

Fig. 9a,b. Epicentral maps of year 2006, showing location quality of revised bulletin (a) and automatic (b) epicenters. The colours are relative to the combined quality factor (normalized from 0 to 10) based on network geometry and statistical location errors (see text and tables III and IV for details). Symbol size is proportional to the magnitude, symbol type depend on hypocentral depths.

liable ML estimates in the whole Italian region. However, for events located at the periphery or outside the network, the ML computation can be biased by the epicentral mislocation.

\section{Quality of Real Time Locations vs. Bulletin Locations}

Years of interactions with the Italian Civil Protection Department (DPC) taught us that one of the main problems seismologists have to face is how to automatically evaluate the reliability of a location and how to communicate it to a non-seismologist in a straightforward way. Unfortunately this is not a simple task due to the bias between the (apparent) possible reduction of the formal errors when reducing the number of data used to locate an earthquake.

To summarize the goodness of the hypocenter solutions we compute two quality rating factors similar to those used in Hypoinverse-2000
(Klein 2002), slightly modified to account for the average station spacing of the RSN (the median of the distances between couples of closest stations is $18.5 \mathrm{~km}$ and the mean is $23.3 \mathrm{~km}$ ). An earthquake is of rank $\mathrm{A}, \mathrm{B}$, or $\mathrm{C}$, with respect to the quality ratings Q1 and Q2, only if it fulfils all the conditions expressed in tables III and IV respectively, or of rank D if at least one of these conditions is contradicted. In order to rank all the earthquakes with a unique number, we assigned a score to each class of the two quality ratings (see tables III and IV). Their sum Q1+Q2 ranges from -4.5 (worst) to 4.5 (best) on a 10 degree scale. Figure 9 shows the quality of all the hypocenter locations in the year 2006 Bulletin (fig. 9a) and in the corresponding (final) automatic solutions (fig. 9b).

As expected, all the earthquakes falling outside the RSN show a low (from pink to purple) rating both in the real-time and in the Bulletin locations. The inaccuracy of these hypocenters is due mainly to the spatial distributions of the 

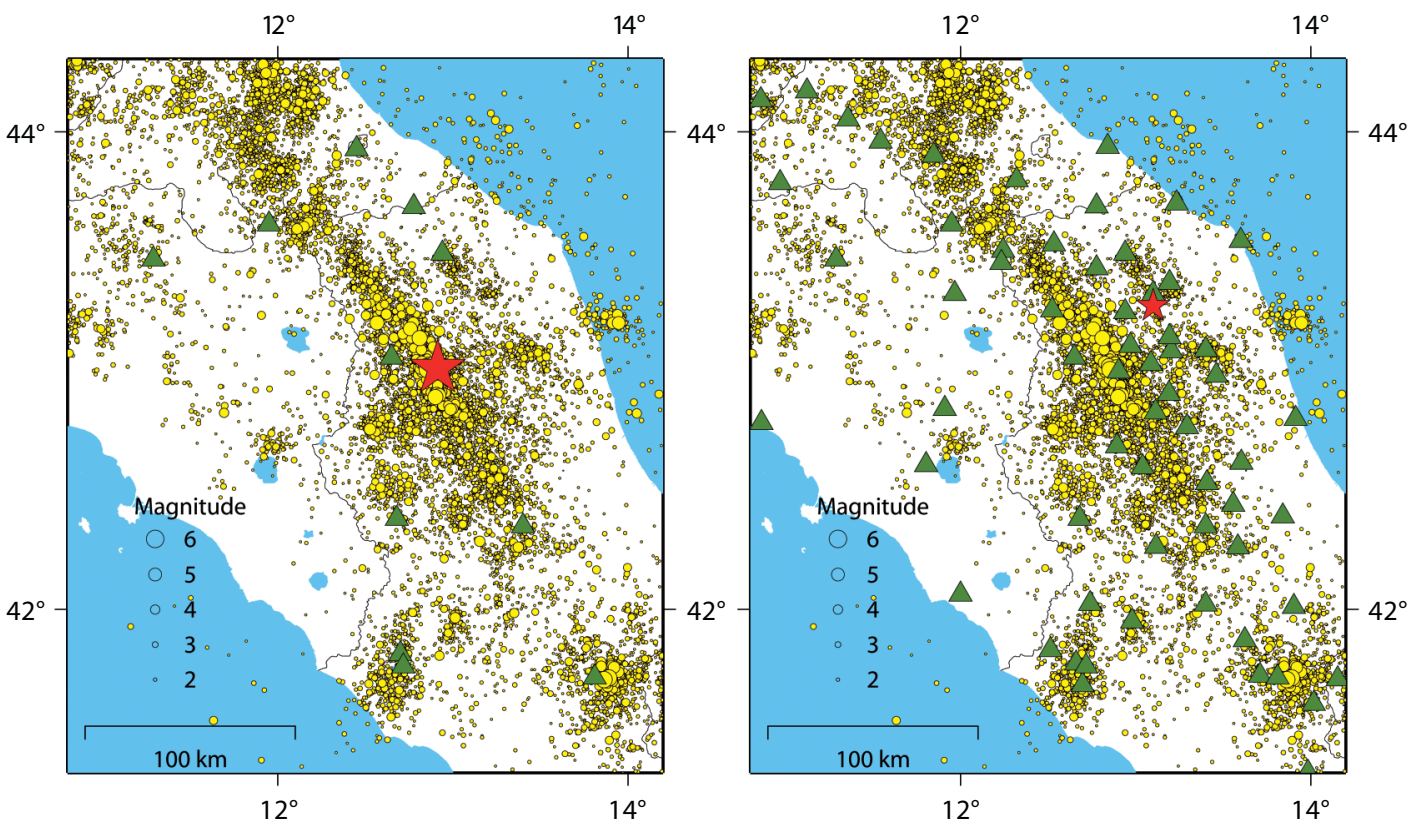

Fig. 10. Comparison between network geometries for the Mw5.8, 1997 Umbria-Marche main shock, and a ML3.1 earthquake that occurred in 2007. The seismic stations are the green triangles, the yellow dots are the 1981-2002 seismicity of the CSI catalogue. The network for the 2007 event includes the RSN and the Marche regional network.

stations around the epicenter, showing a large maximum azimuthal gap and/or a distant closest station.

In the Bulletin (fig. 9a) there is a large prevalence, in peninsular Italy and Sicily, of good quality locations (high ranking from white to dark green) for earthquakes of greater magnitude, while lower quality locations are found for low magnitude earthquakes. Some poor locations can be found in the Bulletin even at greater magnitudes near the coasts or in border regions. The real-time locations (fig. 9b) have in general a lower quality than the Bulletin solutions, as expected. However, a good ranking is observed for all the largest earthquakes (ML 4.0 and above) falling in the peninsula, in the Gargano area, and in Sicily; events with ML around 3.0-3.5 can sometimes have poor rating when falling in costal or border regions. From south to north, good real-time locations are observed around M. Etna, in the southern
Tyrrhenian (intermediate and deep events), the southern Apennines, the Gargano promontory, the Marche region and in the northernmost Apenninic crest. Relatively poor real-time locations (pink colors in fig. 9b) are seen in centralwestern Sicily, the off-shore north of Sicily, Calabria, the Umbria-Marche (surprisingly enough), and all the northern regions. In general, very few earthquakes inland Italy have bad overall ranking (purple colors). Moreover, it must be considered that the RSN improved further during 2007 and 2008, filling some of the gaps of 2006.

\section{Comparison between the locations of the 1997 Umbria-Marche main shock and a small event in 2007}

As described above, the improvement of RSN data availability and quality in the last 10 
years is impressive. When the 1997 main shock occurred, only 6 real-time stations within 100 $\mathrm{km}$ could be used for locating the earthquake, all of which were short-period vertical seismometers connected with low dynamic telephone lines, therefore all of them were saturated. The magnitude ML was estimated after several minutes based on MedNet data, using a few stations in the distance range 50-600 km (stations AQU, VSL, TRI, BNI: Aquila in central Italy, Villasalto in Sardinia, Trieste and Bardonecchia in northern Italy, see also Pino and Mazza, 2000). It must be said, however, that the RSN location was very close to the one relocated by Amato et al. (1998), based on a master event technique, but was provided after several minutes with a large initial uncertainty, due to the low number of close stations and to the impossibility of picking $\mathrm{S}$ waves on saturated vertical traces (F. Pirro, personal communication).

In order to show this improvement with an example, fig. 10 compares the 1997 location and network geometry with those of a small earthquake that occurred 10 years later approximately in the same region (October 7, 2007, ML 3.1). The final automatic location of this earthquake was computed in less than three minutes using a total number of 107 seismic stations, 38 of which within $100 \mathrm{~km}$, with ML determined averaging 93 values (horizontal channels). This includes 94 RSN seismic stations and 13 stations of the regional Marche network RSM (see Monachesi et al., 2004; De Luca et al., 2008). The first automatic location for this event was available after 21 seconds (with 4 RSN stations), and the first ML estimate after about 42 seconds (ML 3.3): a dramatic improvement with respect to the 1997 shock.

\section{Conclusions}

We have shown how the National Seismic Network (RSN) development of the last few years led to the production of much better data than in the 90's, allowing us to better quantify and describe Italian seismicity. The main points arising from our analysis are: a) the performance of the real-time location and magnitude computation during 2006 is very good; b) the comparison with year 2000, before the RSN improvement, shows that more than twice the number of earthquakes were located in 2006, with a minimum magnitude of completeness around ML 1.7 ; c) the frequency-magnitude distribution in 2006 is consistent, with a very well determined $b$-value $(0.84$ between ML 1.6 and 4.8), demonstrating that the ML estimates are finally stable, thanks to the large number of well calibrated three-component seismic stations used; d) the differences between real-time and revised locations are within $10 \mathrm{~km}$ for more than $80 \%$ of the data, with larger errors for offshore and coastal earthquakes; e) the real-time ML estimates (both the final and the rapid one, obtained after 120-240s and 40s, respectively) are generally very good, with $90 \%$ and $85 \%$ of the values within \pm 0.4 from the revised magnitude; f) there are some regions where a network improvement is still desirable: in particular, all the off-shore areas in the Ionian, Tyrrhenian and Adriatic seas, Calabria, western Sicily and some areas in northern Italy.

Many efforts are underway to increase the performance of the real-time monitoring system based on the present high level seismic network: to improve the computation of rapid and accurate shake maps and moment tensor (Michelini et al., 2008) and to test Early Warning systems (Olivieri et al., 2008). Moreover, several studies to constrain the crustal structure and the seismogenic processes in Italy are in progress, thanks to the very high quality data produced by the seismic networks today.

\section{Acknowledgments}

Special thanks to A. Marchetti and all the Seismic Bulletin staff of Centro Nazionale Terremoti (CNT) who analyzed the RSN data; to M. Cattaneo and all the technical staff of CNT who developed the RSN in the last few years; to L. Badiali and the SIR staff of CNT for the data acquisition and storage; to M. Di Bona who directed the Data Center in 2001-2004, to A. Basili, F. Doumaz, A. Bono, who contributed to several parts of the monitoring system. The activities described in this paper were carried out with the support of the Italian «Dipartimento di 
Protezione Civile Nazionale» (DPC). The network development in southern Italy also benefited from the PROSIS project, funded by the Italian Ministry of Research. We thank D. Luzio and an anonymous reviewer for useful suggestions that improved the manuscript.

\section{REFERENCES}

Amato, A., C. Chiarabba and G. Selvaggi (1997): Crustal and deep seismicity in Italy, Ann. Geofis., XL (5), 981993.

AmAтo, A., et al. (1998): The 1997 Umbria-Marche, Italy, earthquake sequence: a first look at the main shocks and aftershocks, Geophys. Res. Lett., 25 (15), 2861-2864.

Amato, A., L. Badiali, M. Cattaneo, A. Delladio, F. DoumAZ, and F.M. Mele (2006): The real-time earthquake monitoring system in Italy, Géosciences (BRGM), vol. 4, 70-75.

Bindi, D., D. Spallarossa, C. Eva and M. Cattaneo (2005): Local and Duration Magnitudes in Northwestern Italy, and Seismic Moment Versus Magnitude Relationships, Bulletin of the Seismological Society of America, 95, 592-604.

Castello, B., G. Selvaggi, C. Chiarabba and A. Amato (2006): CSI Catalogo della sismicità italiana 19812002, (versione 1.1. INGV-CNT, Roma).

Castello, B., M. Olivieri and G. SelvagGi (2007): Local and duration magnitude determination for the Ialian earthquake catalogue (1981-2992), Bulletin of the Seismological Society of America, 97 (1B), 128-139.

Chiarabba, C., L. Jovane and R. Di Stefano (2005): A new view of Italian seismicity using 20 years of instrumental recordings, Tectonophysics, 395 (3-4), 251-268.

Chiaraluce, L., A. Amato, M. Cocco, C. Chiarabba, A. Deshamps, F. Courboulex, M. Di Bona, L. MarcheRiti, G. Selvaggi, D. Piccinini and M. RiPePe (2004): Complex normal faulting in the Apennines thrust and fold belt: the 1997 seismic sequence in Central Italy, Bulletin of the Seismological Society of America, 94 (1), 99-116.

CSTI 1.0 Working Group (2001): Catalogo strumentale dei terremoti italiani dal 1981 al 1996, (CD-ROM versione 1.0, Clueb Bologna).

De Luca, G., M. Cattaneo, G. Monachesi and A. Amato (2008): Seismicity in the Umbria-Marche region from the integration of national and regional seismic networks, Tectonophysics, doi: 10.1016/J.TECTO.2008.11.032.

Deshamps, A., F. Courboulex, S. Gaffet, A. Lomax, J.
Virieux, A. Amato, A. Azzara, B. Castello, C. Chiarabba, G.B. Cimini, M. Cocco, M. Di Bona, L. Margheriti, F. Mele, G. Selvaggi, L. Chiaraluce, D. PICCININI and M. RIPEPE (2000): Spatio-temporal distribution of seismic activity during the UmbriaMarche crisis, 1997, Journal of Seismology, 4, 377-386.

GASPERINI, P. (2002): Local magnitude revaluation for recent Italian earthquakes (1981-1996), Journal of Seismology, 6, 503-524.

GASPERINI, P. (2007): Completezza ed omogeneità del catalogo strumentale Italiano ai fini di studi statistici di occorrenza sismica, XXVI Convegno Gruppo Naz. Geofis. Terra Solida, (CNR, Rome, Italy, Novembre 2007, abstract).

GRUPPO DI LAVORO CPTI (2004): Catalogo Parametrico dei Terremoti Italiani, (versione 2004 (CPTI04), INGV, Bologna).

Huber, P. J. (1981): Robust statistics, (Wiley, N.Y.).

Hutton, L.K. and M. Boore, (1987): The ML scale in southern California, Bull. Seism. Soc. Am., 77, 2074-2094.

KLEIN, F.W. (2002): User's Guide to HYPOINVERSE2000, a Fortran Program to Solve for Earthquake Locations and Magnitudes, USGS Open File Report 02-171, 123, 2002.

Marchetti, A, S. Barba, L. Cucci and M. Pirro (2006): Performances of the Italian Seismic Network, 19852002: the hidden thing, Annals of Geophysics, 49 (2/3), 867-879.

Michelini, A., L. Faenza, V. Lauciani and L. Malagnini (2008): ShakeMap Implementation in Italy, Seimological Research Letters, 79 (5), 689-698.

Monachesi, G., M. Frapiccini, L. Trojani and P. MelONARO (2004): RSM On Line, il DB della Rete Simometrica Marchigiana, Regione Marche, Servizio Protezione Civile, (INGV, Ancona).

Olivieri, M., R. Allen and G. Wurman (2008): The Potential for Early Warning in Italy using ElarmS, Bull. Seism. Soc. Am., 98 (1), doi: 10.1785/0120070054

Peresan, A., G.F. PANZA and G. Costa (2000): CN algorithm and long-lasting changes in reported magnitudes: the case of Italy, Geophys. J. Int., 141 (2), 425-437.

PINO, N.A. and S. MAZZA (2000): The Umbria-Marche (central Italy) earthquakes: relation between rupture directivity and sequence evolution for the $\mathrm{Mw}>5$ shocks, J. Seismol., 4, 451-461.

TACCETTI, Q. F. Mele and.R. Buland (1989): Il sistema automatico per la rilevazione, il processamento e l'archiviazione dei dati della rete sismica nazionale italiana I.N.G., in Aree sismogenetiche e rischio sismico in Italia, edited by E. BoschI and M. DRAGONI, (Lausanne), II, 1-7.

Tinti, S. and F. Mulargia (1987): Confidence intervals of b-values for grouped magnitudes, Bull. Seismol. Soc. Am., 77, 2125-2134. 